\title{
Deans of medicine urge provincial action on residency mismatch
}

\author{
C Cite as: CMAJ 2018 March 5;190:E272. doi: 10.1503/cmaj.109-5574
}

Posted on cmajnews.com on Feb. 13, 2018.

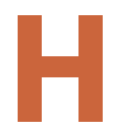

undreds of Canadian medical graduates will be locked out of residency positions by 2021 unless immediate action is taken, according to the Association of Faculties of Medicine of Canada (AFMC).

The number of Canadian medical graduates (CMGs) who don't match to residency positions spiked to 68 last year, up from 46 in 2016 and 11 in 2009. And the mismatch is projected to worsen as more unmatched graduates compete for the same positions year on year. With no changes in the number of graduates and residency positions, "by 2021 the number of current year unmatched CMGs is projected to exceed 140 while prior year unmatched CMGs will exceed 190," AFMC warns. This represents a huge waste of public funding for medical training, as well as a major stressor for medical trainees.

Medical faculties attribute the crisis to a shrinking ratio of residency positions to eligible graduates, which is expected to drop below 1:1 by 2019. In a new strategy, AFMC called on provincial governments to increase the number of residency positions to the historical norm of 1.1 positions per current-year CMG. The association also urged governments to create a dedicated pool of positions to ensure flexibility for transfers between residency programs, and to work together when making decisions that will affect the physician supply.

"Provincial policy decisions can be key drivers to the outcome of the national match," AFMC stated. However, "to date there is no national strategy, planning or implementation to address match outcomes." In recent years, the impact of residency cuts in Ontario has been compounded by an exodus of medical graduates from Quebec in the wake of

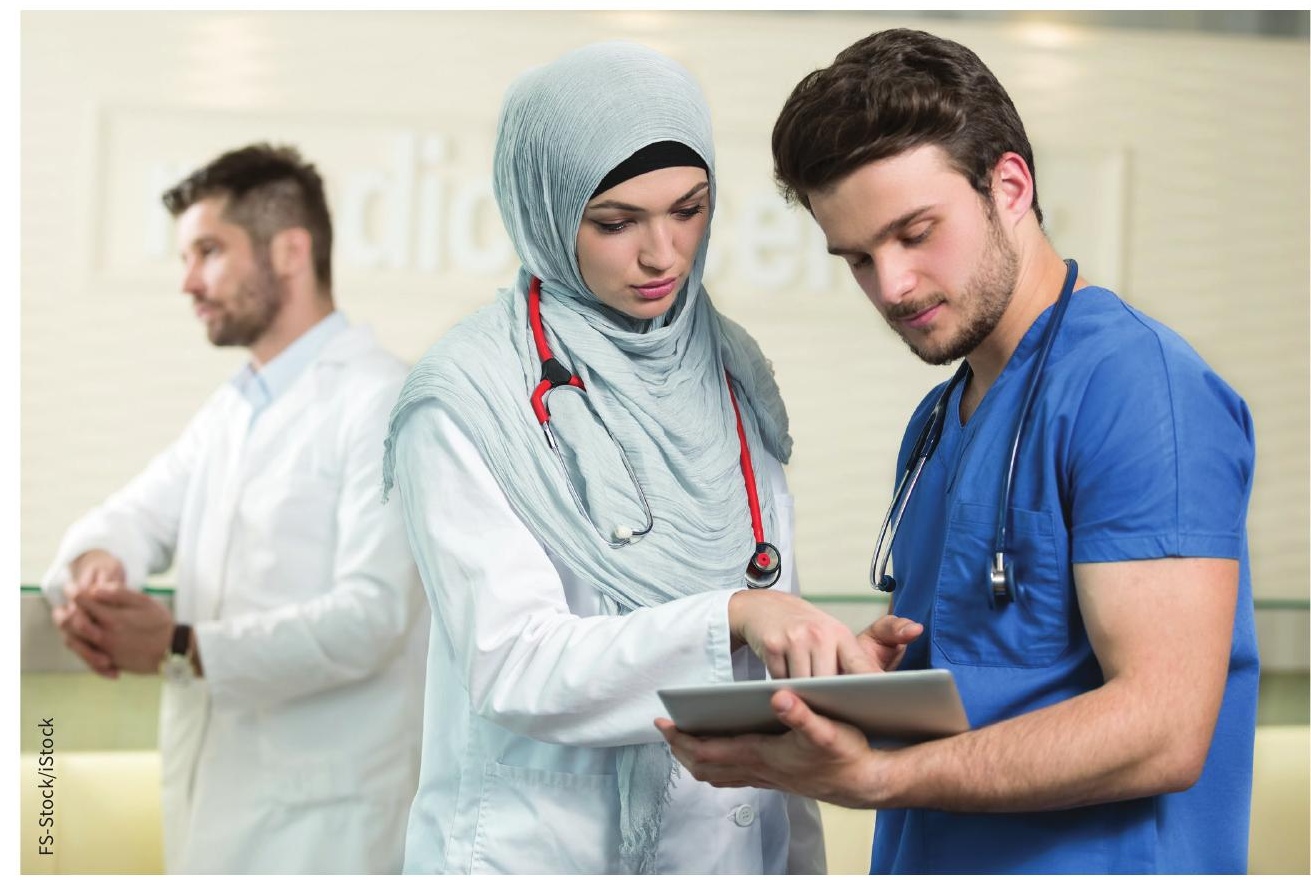

Provinces must increase the number of residency positions to ensure that Canadian medical graduates can finish their training, faculties warn.

unpopular policies to force doctors to see more patients. The ratio of English-speaking positions has dropped to less than one seat per CMG, yet 58 Quebec family medicine spots went unfilled in the second round of last year's match.

An influx of graduates from the United States and other countries further complicates the match. More US medical graduates match to Canadian residency positions than CMGs match to American programs. US graduates also have the advantage of knowing their Canadian match results before the American match takes place. Meanwhile, international medical graduates are filling positions in the second round of the match that were initially slated for CMGs. AFMC is calling for changes to match processes to "maintain the separation of
Canadian medical graduate and international medical graduate streams in the second iteration of the resident match."

Deans of medicine also rejected the notion that unmatched Canadian graduates are somehow unqualified. "About two-thirds or more of unmatched CMGs are applicants who could have matched if positions in those programs were available," AFMC stated. Among other solutions, "faculties take responsibility for creating appropriate structures, policies and procedures to enable them to support their unmatched Canadian medical graduates," including access to additional electives and counselling. Deans will report back on the implementation of these supports in October 2018.

Lauren Vogel, CMAJ 